\title{
Herbage Capacitance Meter: an Evaluation of Its Accuracy in Florida Rangelands
}

\author{
W. STEPHEN TERRY, DENNIS H. HUNTER AND BENEE F. SWINDEL
}

\section{Abstract}

This paper reports results of regression analyses of the use of a capacitance meter to estimate herbage weight. Estimation of dry weights was found to be as accurate as estimation of green weights. Analysis of covariance for three factors, site, season of year, and year of data collection, showed only season significantly $(P<.01)$ affected the relationship between herbage weight and meter reading. Simple linear regressions were compared to natural logarithmic regressions. Logarithmic regressions were found to be better predictors of herbage weight as determined by Furnival's Index. Winter and spring proved to be the best time to use the capacitance meter, probably due to decreased effect of moisture fluctuations on the meter's performance.

Ncal and Neal (1973) reported electronic capacitance meters are accurate for estimating weights of standing vegetation under a wide variety of conditions. Neal and Neal (1965) and Back et al. (1969) concluded that a double sampling procedure (consisting of clipping and weighing a subsample of the plots where meter readings are recorded) can produce rapid, accurate estimates of biomass. Estimation is improved if standing biomass within a three dimensional plot (Currie et al. (1973)) that just encompasses the sensors of the meter is clipped-as opposed to the more conventional clipping of material rooted within a two dimensional plot delineated on the ground. Carpenter et al. (1973) showed that eliminating woody stems from weight measurements also improves herbage estimation. This is in agreement with data of Morris et al. (1976), whose study indicated that the capacitance meter mainly senses plant parts with the highest moisture content. The capacitance of plant moisture is several orders of magnitude higher than that of free water, due principally to the electrolyte content of the former. Consequently, green succulent plants produce considerably higher meter readings than do standing dead material. They both can contribute significantly to variation of regression estimates (Currie et al. (1973)).

Herbage capacitance meters have been used in Florida since 1975 as a nondestructive means of measuring forage production. However, simple linear regressions of dry live weight on meter readings yielded poor predictors, even when regressions were run on a day-to-day basis. Analysis reported here suggests the superiority of separate logarithmic regression models for each of the four seasons of the year.

\section{Study Area and Methods}

Herbage capacitance meters were used in three separate studies at two locations within the state, with both sites having the same basic vegetation type. Two of the studies were conducted in south central Florida flatwoods vegetation type; the third took place in the north Florida flatwoods vegetation type at the University of Florida's Beef Research Unit. South Florida flatwoods vegetation consists principally of small shrubs, forbs, grasses, and grasslikes dominated by Serenoa repens (saw palmetto), Elephantopus tomentosus (elephant's foot), Aristida stricta (pineland threeawn),

\footnotetext{
Authors are research biologist, Range Ecosystem Management, School of Forest Resources and Conservation, University of Florida, Gainesville 3261 1; and currently senior Environmental Engineer, Utah International Incorporated, San Francisco, CA 94104 and formerly assistant professor Range Ecosystem Management, School of Forest Resources and Conservation University of Florida, Gainesville; and research forester, U.S. Dep. Agr. Forest Service, Southeastern Forest Experiment Station Gainesville 32611

This paper is Journal Series No. 1938, Institute of Food and Agricultural Sciences, University of Florida, Gainesville.

Guidance in data collection by Dr. Larry White is gratefully acknowledged.

Manuscript received October 11, 1979.
}

Schizachyrium stolonifer (creeping bluestem), and Rhynchospora spp. (beakrush), respectively. The north Florida flatwoods site contained similar understory vegetation with a greater abundance of trees, mainly Pinus palustris (longleaf pine), and various $Q u e r-$ cus spp. (oaks).

Study sites were sampled using the Model 18-2000 herbage capacitance meter from Neal Electronics, Burbank, California. At cach plot scveral meter readings were taken until they stabilized, and then were recorded. The meter was removed, herbage standing within the space previously occupied by the meter's sensors $(31 \mathrm{~cm}$ $\times 61 \mathrm{~cm} \times 51 \mathrm{~cm}$ ) was clipped, and all standing dead material was removed. The live material was oven-dried at $65^{\circ} \mathrm{C}$ for 48 hours and then weighed. In south Florida 210 such plots were measured in the spring of 1975 , and 290 in the fall. Green weights also were recorded on 210 plots to allow comparison of the predictability of green versus dry weights. The Beef Research Unit site was sampled in 1976 and 1977 where 142 plots were measured in winter (December-February), 233 in spring (March-May), 456 in summer (June-August), and 571 in fall (September-November).

Analysis of covariance, with weight as the response variable and meter reading as the covariable, was used to test for site, season, and year effects and interactions. Logarithmic regressions and linear regressions were compared using Furnival's Index (Furnival 1961). Data were analyzed using the Statistical Analysis System on an Amdahl $470 \mathrm{~V} / 6-11$ with OS/MV Release 3.8 and JES2/NJE Release 3. Computing was done using the facilities of the Northeast Regional Data Center of the State University System of Florida located on the campus of the University of Florida in Gainesville.

\section{Results and Discussion}

A question addressed early was whether dry weights could be predicted as well as green weights based on meter readings. Dry weights had simple correlations with meter readings comparable to those of green weights. Neal et al. (1976) also found that the capacitance meter could accurately predict dry weights of herbage biomass. With this assurance only dry weights were used in all remaining analyses.

An analysis of covariance was conducted to determine whether any of the factors (site, season, or year of data collection), or their interactions, affect dry weights adjusted for meter readings. The results indicated that the only significant $(P<.01)$ factor was season of the year.

Simple linear regressions of dry weights on meter readings were plotted for each of the four seasons. The resulting graphs suggested that a logarithmic regression model resulted in a better fit than a linear model. The linear regression model fitted was

$$
W=a_{0}+a_{1} w+\epsilon,
$$

where $W=\mathrm{dry}$ weight, $w=$ meter reading, $\epsilon$ is random error, and $a_{0}$ and $a_{1}$ are regression coefficients estimated from the data. The logarithmic regression model was

$$
\ln W=\mathrm{b}_{\mathrm{o}}+b_{1} \ln w+\sigma
$$

where $\ln w=$ natural $\log$ of dry weight $\ln w=$ natural $\log$ of meter reading, $\sigma$ is a random error, and $b_{0}$ and $b_{1}$ are regression coefficients from the transformed data. 


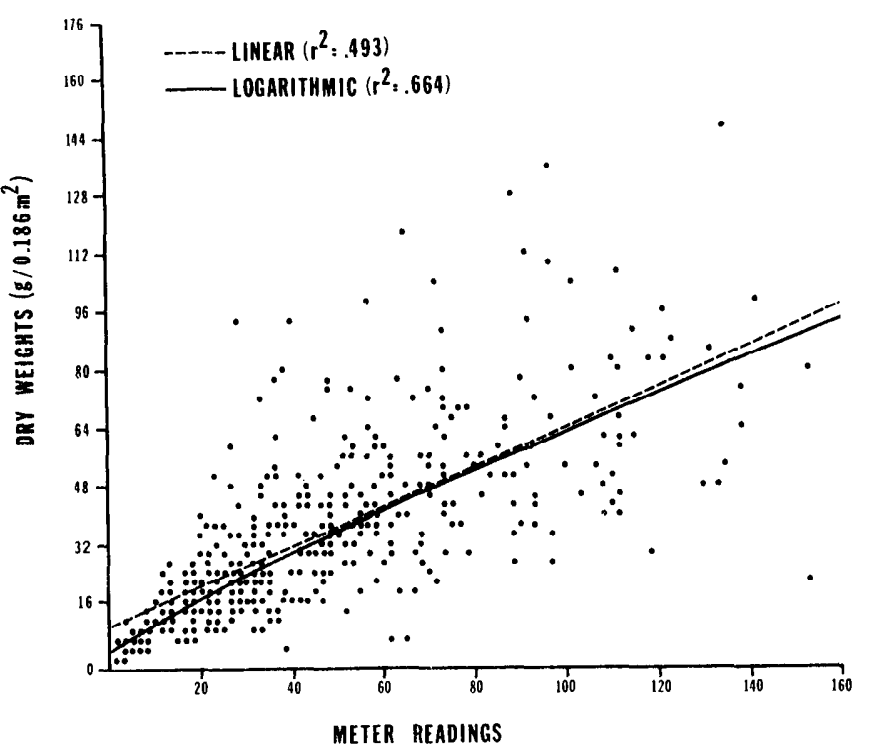

Fig. 1. Simple linear and logarithmic regressions showing the relationship of the regressions to the plotted data for summer season (466 obs.).

Table 1 gives various statistics for the fitted linear and logarithmic regression models for individual season and for the full year. Clearly individual seasonal regressions fit better (have equal or higher $r^{2}$ values) than the full year model, with the exception of summer. The descending order of $r^{2}$ values is winter, spring, fall, full year, and summer for both regression types. This ranking can be partially explained because the herbage meter measures the capacitance of standing herbaceous vegetation (Neal Electronics 1975). Any variable that affects this capacitance (e.g., water or moisture content), while not affecting the dry weight of the plot, reduces the merit of the regression relation. Thus, highest $r^{2}$ values for both regression types were in the winter season when plants are mostly dormant with low and stable moisture content. Conversely, during the summer, actively growing plants, high and variable humidity, and frequent thunderstorms result in high fluctuations of moisture levels daily, even hourly. This undoubtedly produced greater variability in meter readings and poorer regression relations.

When comparing linear and loga rithmic models, the logarithmic models have higher $r^{2}$ values than linear ones. Figure 1 shows both fitted regression lines plotted against the observations for the summer seasonal data. As seen in this graph, the logarithmic regression line reflects the curvature of the data and produces an apparent better fit.

Standard errors of alternative regression modesl are not directly comparable to determine which is better unless the dependent variables are identical (Furnival 1961). Furnival's Index adjusts the standard errors of regression in order to facilitate this comparison. The index for the linear regression of equation (1) is:

$$
I_{1}=S_{1}
$$

Table 1. Statistics of fit for linear and logarithmic regressions of herbage dry weight on capacitance meter reading $\left(a_{0}, a_{1}, b_{0}\right.$ and $b_{1}$ are estimated regression coefficients, and $r^{2}$ is coefficient of determination).

\begin{tabular}{|c|c|c|c|c|c|c|c|}
\hline \multirow{2}{*}{$\begin{array}{l}\text { Season of } \\
\text { the year }\end{array}$} & \multirow{2}{*}{$\begin{array}{l}\text { No. of } \\
\text { obs. }\end{array}$} & \multicolumn{3}{|c|}{ Linear } & \multicolumn{3}{|c|}{ Logarithmic } \\
\hline & & $a_{0}$ & $a_{1}$ & $\mathrm{r}^{2}$ & $b_{o}$ & $b_{1}$ & $\mathrm{r}^{2}$ \\
\hline All & 1612 & 14.619 & 0.537 & .593 & 0.718 & 0.763 & .716 \\
\hline Winter & 142 & 4.351 & 1.587 & .802 & 0.363 & 0.911 & .823 \\
\hline Spring & 443 & 5.405 & 0.976 & .777 & 0.160 & 0.918 & .823 \\
\hline Summer & 456 & 9.951 & 0.542 & .493 & 0.126 & 0.837 & .664 \\
\hline Fall & 571 & 14.545 & 0.479 & .670 & 0.252 & 0.711 & .716 \\
\hline
\end{tabular}

Table 2. Furnival's Index for comparison of linear and logarithmic regression equations by season and full year.

\begin{tabular}{lcc}
\hline \hline Season of the year & Linear & Logarithmic \\
\hline All & 21.42 & 15.48 \\
Winter & 12.77 & 8.44 \\
Spring & 17.57 & 13.13 \\
Summer & 17.67 & 13.02 \\
Fall & 20.29 & 17.71 \\
\hline
\end{tabular}

where $I_{1}=$ index for equation (1), and $S_{1}=$ standard error of regression for equation (1). The Index for the logarithmic regression of equation (2) is:

$$
I_{2}=S_{2} \cdot e^{\bar{y}}
$$

where $I_{2}=$ index for equation (2), $S_{2}=$ standard error of regression for equation (2), $e^{y}=$ antilog of mean of natural logs of dry weights. Computed indices are shown in Table 2.

Indices are interpretable as standard errors of regressions such as those in Figure 1, so lower index numbers indicate better fits (Furnival 1961). Thus Furnival's Index also indicates that the logarithmic regressions are better models than the linear ones.

\section{Summary and Conclusions}

Dry weight of forage can be predicted from capacitance meter readings, although not without error. Comparisons based on scatter graphs, coefficents of determination, and Furnival's indices all suggest that predictability is improved if both dry weights and meter readings are expressed on logarithmic rather than linear scales. And predictability is improved if the data are partitioned according to the season in which they are collected.

Predictability is poorest in summer when various meterological and micro-climatological factors can perturb capacitance meter readings. Predictability is best in winter and spring when these perturbations are less severe in Florida. These latter seasons (especially winter) are the most critical times for determining cattle grazing capacity because forage production and nutrition are at their lowest annual levels for Florida rangelands.

Sites with more homogeneous vegetation and less moisture variation than those sampled in Florida should produce better predictions of herbage biomass from meter readings.

\section{Literature Cited}

Back, H.L., F.E. Alder, and B.G. Gibbs. 1969. An evaluation of an electronic instrument for pasture yield estimation. Part 2. Use with double sampling for regression estimation. J. Br. Grassl. Soc. 24:168-172.

Carpenter, L.H., D.C. Wallmo, and M.J. Morris. 1973. Effect of woody stems on estimating herbage weights with capacitance meter. J. Range Manage. 26:151-152.

Currie, P.O., M.J. Morris, and D.L. Neal. 1973. Uses and capabilities of electronic capacitance instruments for estimating standing herbage. Part 2. Sown ranges. J. Br. Grassl. Soc. 28:155-160.

Furnival, G.M. 1961. An index for comparing equations used in volume tables. Forest Sci. 7:337-341.

Morris, M.J., K.L. Johnson, and D.L. Neal. 1976. Sampling shrub ranges with an electronic capacitance instrument. J. Range Manage. 29:78-81.

Neal, Donald L., and Lee R. Neal. 1965. A new electronic meter for measuring herbage yield. U.S. Forest Serv. Res. Note PSW-56. 4 p. illus.

Neal, Donald L., and J.L. Neal. 1973. Uses and capabilities of electronic capacitance instruments for estimating standing herbage. Part 1. History and development. J. Br. Grassl. Soc. 28:81-89.

Neal, Donald L., P.o. Currie, and M.J. Morris. 1976. Sampling herbaceous vegetation with an electronic capacitance instrument. J. Range Manage. 29:74-77.

Neal Electronics. 1975. Manual for herbaceous meter model 18-2000. 24 p. 